\title{
REV ISTA
}

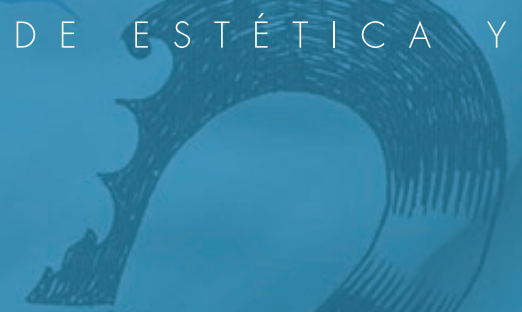

TEORIA

$D E$

LAS

A RTES

No $4 \cdot 2017 \cdot$ ISSN $2386-8449$

\section{CONVERSANDO CON}

"Más allá, pero aquí mismo", Entrevista con José Jiménez, por Miguel Salmerón Infante

UT PICTURA POESIS

Apuntes (1993-1998), Antonio Campillo

Dichoso aquel que no tiene patria, Poemas de Hannah Arendt, versiones de Anacleto Ferrer

PANOORAMA: ESTÉTICA DE LAS CREACIONES ESCÉNICAS Sección coordinada por Antonio Notario Ruiz

TEXTO INVITADO: O silêncio do tempo do silêncio, Fernando José Pereira

TEXTO. INVITADO: Ética y poética en el juego teatral de Reikiavik de Juan Mayorga, Zoe Martín Lago

El problema de la autonomía del teatro, Adrián Pradier Sebastián

¿Qué hubiera sido de Edipo sin Aristóteles y sin Freud? Sebastián Gámez Millán

Como actores en el gran teatro del mundo, Roger Ferrer Ventosa

Mahagonny: surrealismo y dialéctica de la anarquía. Apuntes desde T.W. Adorno, Marcelo Jaume Teruel

Nauman, Mirecka, Rainer: entre el cuerpo y el signo, Laura Maillo Palma

El espacio relativo de Newton y la trasformación de las prácticas escénicas en el teatro moderno, Raúl Pérez Andrade

Sturm und Drang. El drama del genio y Shakespeare, Milagros García Vázquez

MISCELÁNEA

Velázquez y el origen de la modernidad filosófica, Carlos M. Madrid Casado

Duchamp según Jean Clair vs. Arthur Danto, a 100 años de la Fuente, Andrea Carriquiry

Alegoría barroca e imagen dialéctica: el esfuerzo de Walter Benjamin y Theodor W. Adorno para pensar la dialéctica de la naturaleza y la forma estética, Vanessa Vidal Mayor

La idea de tradición en la estética de Jan Mukařovský, Raúl Sanz García

De la visión y el espanto: el tacto suspendido y la experiencia ante el límite, Rayiv David Torres Sánchez

Desrealizando el mundo objetivo: sobre la inmanencia de lo artístico en la fenomenología estética de M. Henry, Jaime Llorente Cardo

Estudios Visuales. Giros entre la crítica de la representación y la ciencia de la imagen, Sergio Martínez Luna

Épica en el arte: el caso de la cảnción de autor, Gustavo Sierra Fernández

El cine más allá de la narración de Lisandro Alonso, Horacio Muñoz Fernández

Perdidos en la isla de los prodigios: Lost o el abismo alegórico del drama barroco, Ainhoa Kaiero Clave

RESENAS

EDITA

\section{SEyTA.}

SOCIEDAD ESPAÑOLA
DE ESTETICAY TEORIA DE LAS ARTES 


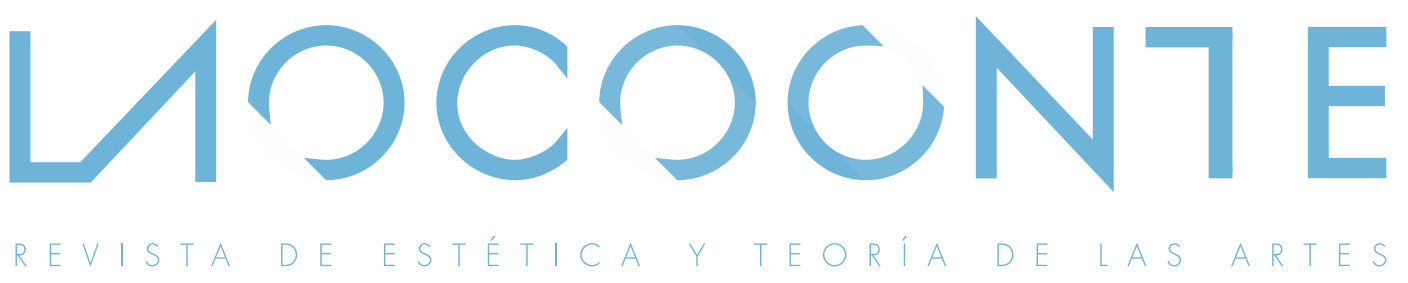

$\mathrm{N}^{\circ} 4 \cdot 2017$

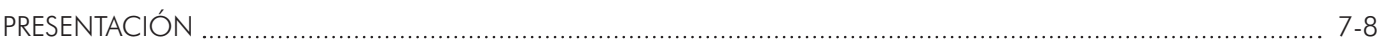

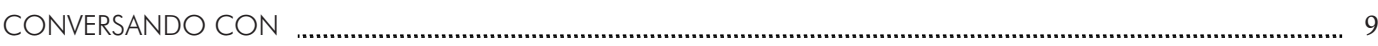

"Más allá, pero aquí mismo", Entrevista con José Jiménez, por Miguel Salmerón Infante .......................... 11-21

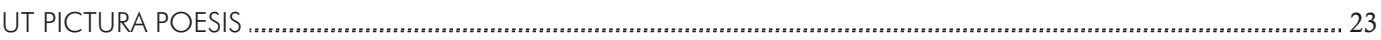

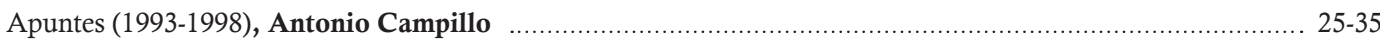

Dichoso aquel que no tiene patria, Poemas de Hannah Arendt, versiones de Anacleto Ferrer .............................. 37-49

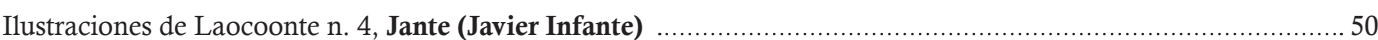

PANORAMA

ESTÉTICA DE LAS CREACIONES ESCÉNICAS _. _ _ _ _. sil

¿Qué hubiera pensado Wagner? Antonio Notario Ruiz (Coordinador) .......................................................... 53-55

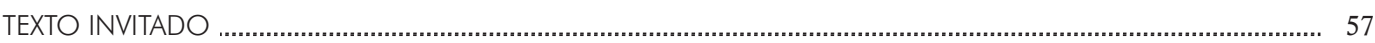

O silêncio do tempo do silêncio, Fernando José Pereira …....................................................................... 59-63

Ética y poética en el juego teatral de Reikiavik de Juan Mayorga, Zoe Martín Lago …..................................... 64-72

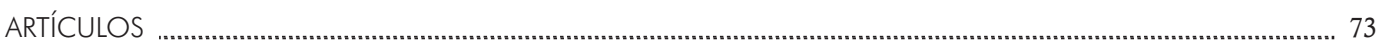

El problema de la autonomía del teatro, Adrián Pradier Sebastián . ....................................................... 75-92

¿Qué hubiera sido de Edipo sin Aristóteles y sin Freud? Sebastián Gámez Millán ........................................ 93-108

Como actores en el gran teatro del mundo, Roger Ferrer Ventosa ........................................................ 109-125

Mahagonny: surrealismo y dialéctica de la anarquía. Apuntes desde T.W. Adorno, Marcelo Jaume.Teruel... 126-133

Nauman, Mirecka, Rainer: entre el cuerpo y el signo, Laura Maillo Palma ............................................. 134-145

El espacio relativo de Newton y la trasformación de las prácticas escénicas en el teatro moderno,

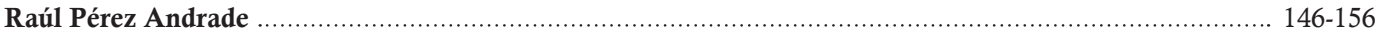

Sturm und Drang. El drama del genio y Shakespeare, Milagros García Vázquez ...................................... 157-168

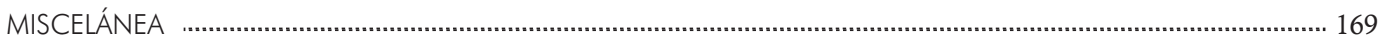

Velázquez y el origen de la modernidad filosófica, Carlos M. Madrid Casado .......................................... 171-181

Duchamp según Jean Clair vs. Arthur Danto, a 100 años de la Fuente, Andrea Carriquiry _ 18.…………... 182-198

Alegoría barroca e imagen dialéctica: el esfuerzo de Walter Benjamin y Theodor W. Adorno para pensar la dialéctica de la naturaleza y la forma estética, Vanessa Vidal Mayor .................................................... 199-213

La idea de tradición en la estética de Jan Mukařovský, Raúl Sanz García ................................................... 214-231

De la visión y el espanto: el tacto suspendido y la experiencia ante el límite, Rayiv David Torres Sánchez .... 232-240

Desrealizando el mundo objetivo: sobre la inmanencia de lo artístico en la fenomenología estética

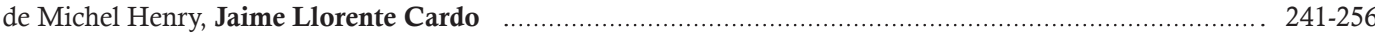


Estudios Visuales. Giros entre la crítica de la representación y la ciencia de la imagen,

Sergio Martínez Luna

Épica en el arte: el caso de la canción de autor, Gustavo Sierra Fernández

El cine más allá de la narración de Lisandro Alonso, Horacio Muñoz Fernández

Perdidos en la isla de los prodigios: Lost o el abismo alegórico del drama barroco, Ainhoa Kaiero Claver

RESEÑAS

Teorías del arte desde el siglo XXI, Pedro Lecanda Jiménez-Alfaro

Rimada Botánica, Xaverio Ballester

Sobre ciudades y arquitecturas, Jürgen Misch

Esbozo de una amistad sempiterna. Sobre Fuster y Alfaro, Raquel Baixauli

Cómo se analiza una obra de teatro, Teresa Aguado Garzón

Vuelan las imágenes, Verónica Perales Blanco

Mudanzas Espacio-temporales. Imagen y memoria, Raimon Ribera

$342-345$

Qué quieren las imágenes? Una crítica a la cultura visual, Esther González Gea

346-349

Zoos humanos, ethnic freaks y exhibiciones etnológicas, Lurdes Valls Crespo

350-353

España de la Guerra, Amanda del Rey Mateos

354-356

Benjamin, Barthes y la singularidad de la fotografía, Jorge Martínez Alcaide

$357-360$

Arte escrita: texto, imagen y género en el arte contemporáneo, Óscar Ortega Ruiz

$361-363$

Sobre el futuro del estudio del pasado, Ana Meléndez 364-366

Conducir a una diosa, Sergio Requejo Pérez

367-370

Cioran en los Archives paradoxales. (Tome III), Joan M. Marín

Género, memoria y cultura visual en el primer franquismo, Raquel Baixauli

La eternidad de un día, Carmen Martínez Sáez

Lo diabólico, lo demónico, lo fáustico en la literatura, la música y el arte, Mauro Jiménez

Circuit Circus. Circo, Intelectuales y Payasos, Ricard Silvestre

Ilustraciones de Jante (Javier Infante).

Fotografía de portada de Tamara Djermanovic intervenida con ilustración de Jante (Javier Infante). 


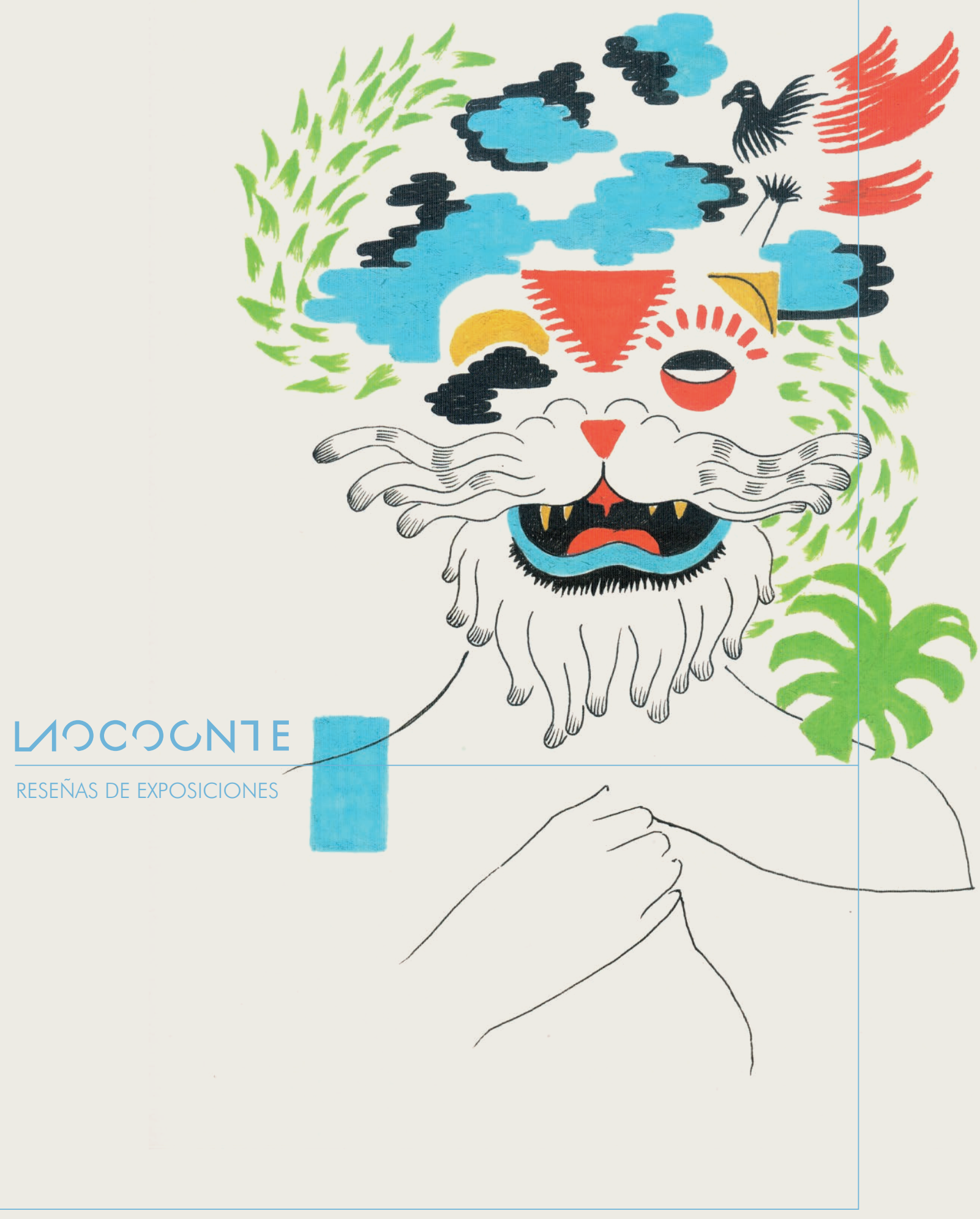


Exposición

\section{Hijo del Laocoonte. Alonso Berruguete y la Antigüedad pagana}

Museo Nacional de Escultura, Valladolid, España, 2017.

María Luisa Barrio Maestre*

\section{Reflexiones sobre el Laocoonte y sus "hijos"}

Del efecto sobrecogedor que el descubrimiento del Laocoonte causó en Alonso Berruguete y otros artistas de su época; de la creación de un nuevo imaginario con base en la Antigüedad pagana y del desarrollo de un nuevo lenguaje artístico trata la exposición que el Museo Nacional de Escultura de Valladolid ha presentado bajo el título Hijo del Laocoonte. Alonso Berruguete y la Antigüedad pagana.

En La Eneida (lib. II, v. 199 a 224) Virgilio relata:

Laocoonte, a quien la suerte había hecho gran sacerdote de Neptuno, inmolaba con solemnidad un soberbio toro sobre los altares del dios. Y he aquí que de pronto [...], salidas de Tenedos, sobre un mar en calma, dos enormes serpientes se alargan sobre las aguas, y desarrollando sus espirales inmensas, avanzan hacia la orilla. [...] Las serpientes, con un común impulso, van derechas hacia el gran sacerdote; primeramente, se lanzan sobre sus dos hijos, rodéanles con horrible abrazo y desgarran con crueles mordeduras el cuerpo de estos infortunados jóvenes. Después se apoderan del padre mismo, que venía, con un hacha en la mano, en socorro de sus hijos. [...] Él, mojado por su repugnante baba, y asqueado por el negro veneno que mancha sus bandas sagradas, resiste con sus brazos rígidos contra estos horribles nudos y lanza hacia el cielo gritos, espantosos.

Este espeluznante relato nos remite ineludiblemente al conjunto escultórico de época helenística que lo representa, creado por Agesandro, Polidoro y Atenodoro de Rodas, y que hoy en día se puede contemplar en los Museos Vaticanos (Fig. 1) ${ }^{1}$.

La excepcionalidad de una escultura creada por tres artistas y "firmada", unido a una referencia literaria de vital importancia descrita por Plinio el Viejo en su Naturalis historia (XXXVI, 37) -la principal fuente literaria de la Antigüedad-convierten el hallazgo del Laocoonte, acaecido en 1506, en un hecho trascendental para la historia del arte.

Alonso Berruguete, hijo del pintor Pedro Berruguete (h.1445/50-1503), había emprendido un viaje de formación a Italia. Encontrándose él allí tuvo lugar el descubrimiento del Laocoonte en una viña cerca de Santa María la Mayor. El Papa Julio II encargó a su hombre de confianza, Giuliano da Sangallo (1445-1516), inspeccionar el hallazgo.

1 Desde su hallazgo en 1506 se han realizado múltiples copias de este conjunto escultórico.

* Universidad Autónoma de Madrid, España.mlbarriomaestre@yahoo.es 


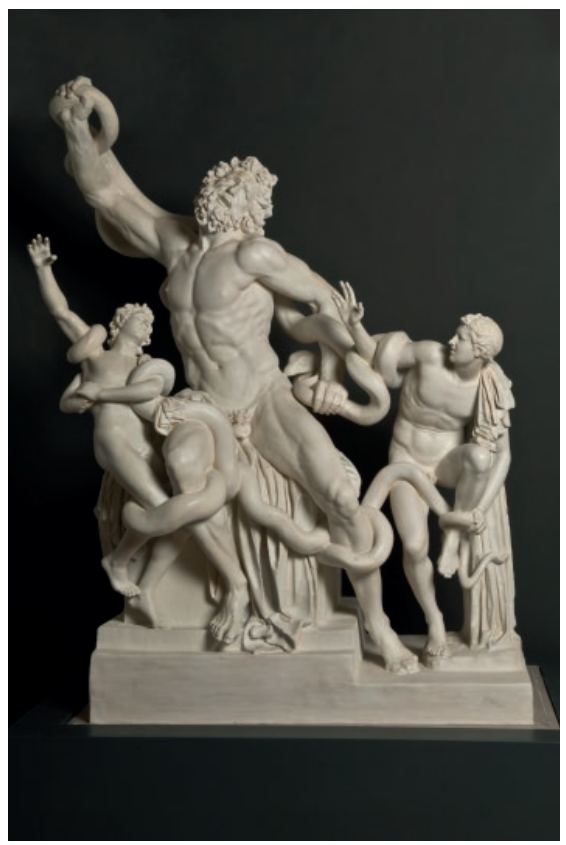

Fig. 1: José Trilles

Laocoonte y sus hijos, 1887

Museo Nacional de Escultura

(Copia del Laocoonte original de los Museos Vaticanos)

Francesco da Sangallo (1494-1576)² relata así el descubrimiento del Laocoonte:

Al Papa le hablaron del hallazgo de unas estatuas muy bellas cerca de Santa Maria Maggiore [...] El Papa ordenó a uno de sus funcionarios que corriera a decirle a Giuliano da Sangallo que fuera a verlas. Este se puso en camino inmediatamente. Como Miguel Ángel Buonarroti estaba siempre en nuestra casa [...], mi padre quiso que fuese con él también. Yo me uní a mi padre y allá fuimos. Bajé adonde estaban las estatuas cuando mi padre dijo inmediatamente: "Ese es el Laocoonte, el que menciona Plinio". Entonces ensancharon el hoyo para poder sacar la estatua. Tan pronto quedó a la vista, todo el mundo empezó a dibujar, mientras se comentaban cosas de la Antigüedad [...]. (Arias Martínez et al. 2017:157-158).

En la biografía de Jacopo Sansovino (1477-1570) Giorgio Vasari (1511-1574) narra que

Habiendo visto Bramante [...] los dibujos de Jacopo, le cobró tal amistad, que le encargó que modelara en cera el grupo del Laocoonte, que también copiaban el español Alonso Berruguete, Zaccheria Zachi da Volterra, y el Vecchio de Bolonia, para fundirlo en bronce. Cuando los modelos estuvieron acabados Bramante los mostró a Rafael Sanzio de Urbino, rogándole que decidiera cuál era el mejor. Rafael juzgó que Sansovino, a pesar de su juventud, sobrepasaba a todos sus rivales. Entonces el cardenal Domenico Grimani ordenó la fundición en bronce del modelo de Sansovino [...]. (Arias Martínez et al. 2017: 158) .

El capítulo del descubrimiento del Laocoonte fue trascendental desde el punto

2 Hijo de Giuliano da Sangallo, quien encomendó a Miguel Ángel Buonarroti la creación del sepulcro del Papa Julio II en San Pietro in Vincoli.

3 Arias Martínez, Manuel et al. catálogo de la exposición Hijo del Laocoonte. Alonso Berruguete y la Antigüedad pagana, en Museo Nacional de Escultura Valladolid, 2017. 
de vista histórico-artístico, ya que impulsó la creación de un imaginario que llegó a difundirse por toda Europa.

La exposición que hoy nos ocupa ha sido comisariada por Manuel Arias Martínez, subdirector del Museo Nacional de Escultura de Valladolid y uno de los mayores expertos en Berruguete. Conforma el recorrido de esta muestra una acertada selección de sesenta y siete obras, de las cuales veintitrés son obra de Berruguete. Con la intención de situar a Berruguete en su contexto, la exposición acoge treinta y tres obras de artistas españoles e internacionales, de la talla de Diego de Siloé, Pedro Machuca, Andrea Palladio, Étienne Dupérac, Marco Dente, Francisco de Holanda o Guiot de Beaugrant. Finalmente, con ayuda de otras catorce obras, prestadas entre otros por el Museo Arqueológico Nacional y el Museo del Prado, Arias Martínez consigue una delicada puesta en valor de obras de la Antigüedad como fuente inagotable de inspiración.

Una exposición multidisciplinar, en la que podemos contemplar esculturas, pinturas, dibujos, grabados, retablos, lápidas funerarias y sarcófagos, todo ello con un ponderado diseño de montaje, secciones bien estructuradas, salas equilibradas, dando protagonismo a todas y cada una de las obras, procedentes en su mayoría de colecciones públicas y privadas españolas, a excepción de un dibujo de Berruguete procedente de las Gallerie degli Uffizi.

Lamentablemente a día de hoy apenas se conservan dibujos de Berruguete y sorprende la total inexistencia de cuadernos de apuntes en un artista que, sin lugar a dudas, debió de dibujar incesantemente, puesto que el dibujo era el eje fundamental de cualquier artista. Este aspecto constituye una posible e interesante vía de investigación. Afortunadamente se pueden contemplar en esta muestra dos de los escasos dibujos conocidos de Berruguete: uno de ellos inédito descubierto recientemente en la Real Chancillería de Valladolid, de cuyo tribunal fue escribano el propio Berruguete; y el dibujo de la Circuncisión de las Gallerie degli Uffizi.

Pero, en nuestra opinión, la originalidad de esta muestra radica fundamentalmente en su concepto. Solemos inscribir a Alonso Berruguete dentro de esa corriente de escultores clásicos, de carácter austero, geográficamente adscritos a Castilla y cuya producción es principalmente de temática religiosa. No obstante, Berruguete como todo gran artista, muestra su genialidad a través de un lenguaje innovador, en el que la expresión será una constante a lo largo de toda su producción. Descubrimos en esta exposición la figura de un artista español que bebe de las fuentes de la Antigüedad y las reinterpreta, llegando a crear un estilo único y personal. Todo ello con una brillante puesta en escena cargada de teatralidad e inteligentes diálogos entre el pasado clásico y la España de Berruguete ${ }^{4}$.

Vicenzo Farinella, en uno de los ensayos del catálogo, dice que "Berruguete fue un artista fulminado por el Laocoonte, quizás el escultor del siglo XVI que más manifiesta a lo largo de toda su extensa carrera el efecto sobrecogedor del Laocoonte" (Arias Martínez et al. 2017: 32-33). Este fue, en opinión del comisario, el punto de partida esencial para comprender la obra de Berruguete. Y es que el rostro del Laocoonte se va

4 En esta muestra cuasi perfecta echamos de menos una información más detallada sobre las técnicas artísticas de cada obra, tanto en las cartelas como en el catálogo de la exposición. Por otro lado, en el catálogo, la fotomecánica, el tipo de papel, la impresión y la encuadernación no hacen justicia a la calidad de la muestra. Afortunadamente los textos pasarán a ser una excelente fuente de investigación. 
a convertir en icono para Berruguete e icono expresivo para la posteridad.

Con gran acierto, y por primera vez en una exposición, Arias Martínez, despliega toda una suerte de diálogos y paralelismos entre la Antigüedad pagana y Alonso Berruguete. Lo que más nos sorprende, según nos adentramos en el mundo Berruguete, es que sólo recibió encargos de temas religiosos. No se le conoce obra profana, a excepción de un dibujo de Leda en el Rijksmuseum de Ámsterdam y otro en la Hispanic Society representando la Decoración de la galera para la coronación imperial de Carlos V; sin embargo, de manera magistral y expresiva, consiguió crear un universo visual propio, en el que integró las mejores aportaciones de la Antigüedad. Motivos paganos que Berruguete cristianiza para introducirlos en retablos, conjuntos escultóricos, lápidas funerarias o esculturas de bulto redondo. En el imaginario de Berruguete lo pagano y lo cristiano tienen puntos de conexión, putti y amorcillos se mezclan con ángeles, sibilas y musas como alegorías de las virtudes, algo que Miguel Ángel ya había realizado con los ignudi o las sibilas en la Capilla Sixtina (Fig.2).

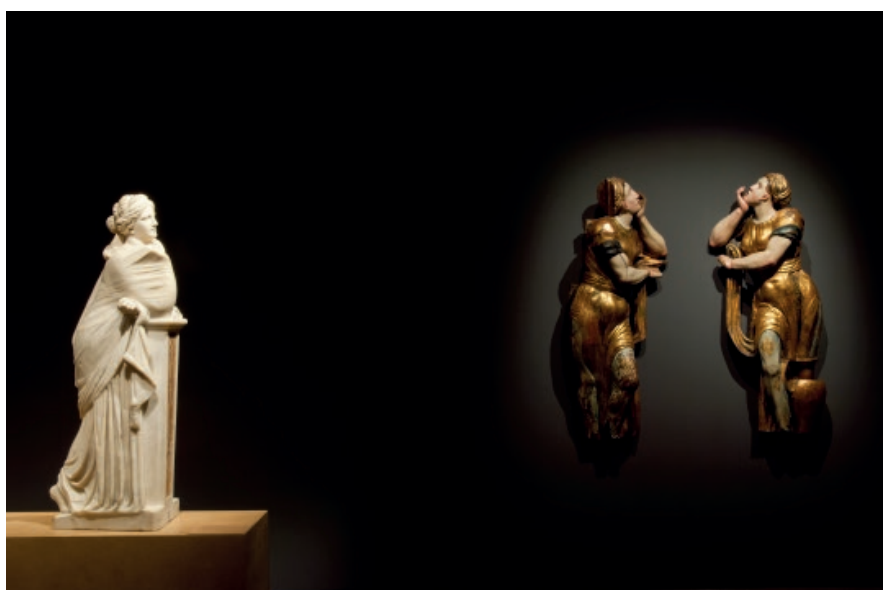

Fig. 2: Imagen de la exposición con:

Anónimo romano

Musa pensativa (izda.)

Museo Nacional del Prado

Alonso Berruguete

Pareja de sibilas del retablo de San

Benito el Real (dcha.)

Museo Nacional de Escultura

Berruguete utiliza toda una serie de recursos formales procedentes de la Antigüedad, como la solución del equilibrio de la figura del Ecce Homo, en la que acude al recurso de apoyar el manto a modo de soporte; una solución ya empleada por artistas romanos como se muestra en el Joven Pan con flauta travesera (Fig. 3).

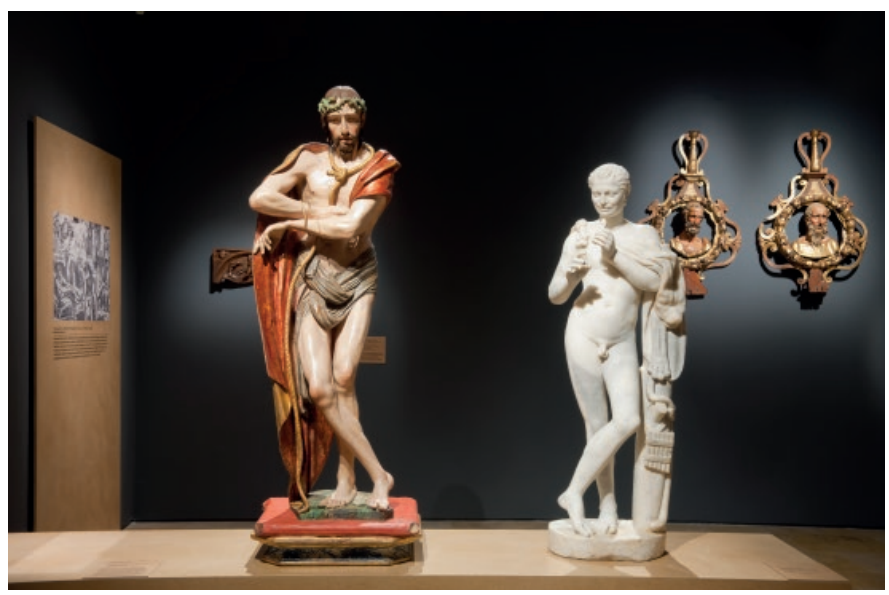

Fig. 3: Imagen de la exposición con: Alonso Berruguete Ecce Homo (izda.) Museo Nacional de Escultura Anónimo romano Joven Pan con flauta travesera (dcha.) Museo Nacional del Prado 
Por encima de todo, a Berruguete le interesa la búsqueda de la expresión. Los recursos que emplea en el rostro -el ceño fruncido, la boca entreabierta- son una reinterpretación de los modelos clásicos. En este sentido llama poderosamente la atención la recurrencia a la boca entreabierta. Uno de los ejemplos más claros es la figura de San José en la escena de La Natividad en el Retablo de la Epifanía de la Iglesia de Santiago en Valladolid, una auténtica relectura del Laocoonte, es el Laocoonte de Berruguete (Fig. 4).

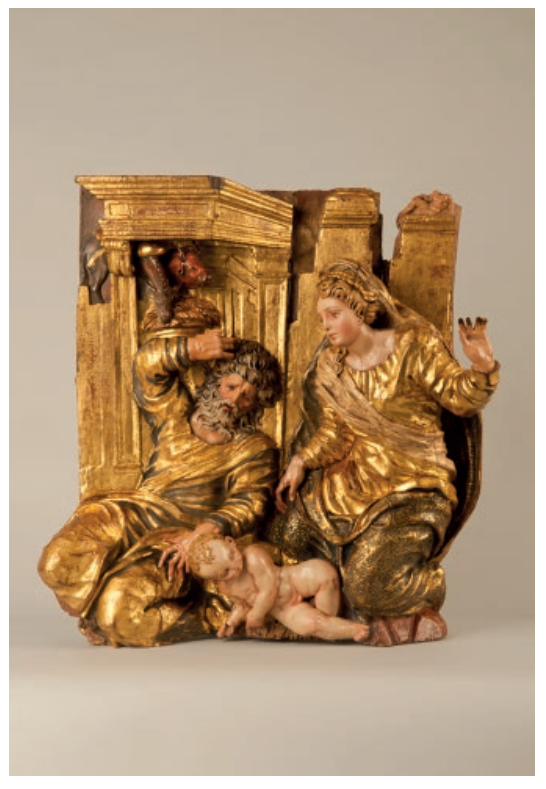

Fig. 4: Alonso Berruguete Natividad

Retablo de la Epifanía

Iglesia de Santiago, Valladolid

En un perfecto juego de simbiosis, a lo largo del recorrido de esta exposición observamos elementos muy comunes del Renacimiento italiano; grutescos y mascarones inspirados en la decoración de la Domus Aurea reproducidos en tondos y retablos (Fig. 5).

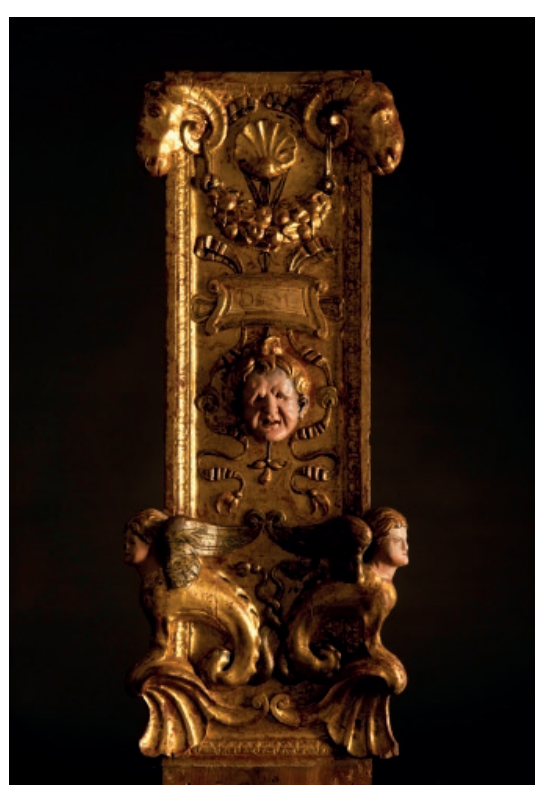

Fig. 5: Alonso Berruguete

Pilastra

Retablo mayor de San Benito el Real, Museo

Nacional de Escultura 
La muestra es una oportunidad única para contemplar de cerca figuras y partes de retablos que por lo general vemos a gran distancia, adentrándonos en una suerte de realidad virtual de lo que fue el retablo de Berruguete en sus orígenes.

Las posturas imposibles de las figuras de San José y el Niño (Fig. 4); las formas serpenteantes de los paños, que recuerdan el movimiento de las serpientes devorando al Laocoonte; las cabezas de carnero, grifos (Fig. 5), sibilas y veneras, todo ello remite ineludiblemente a la Antigüedad pagana.

Además de las esculturas de bulto redondo, los relieves de sarcófagos antiguos fueron otra fuente de inspiración inagotable para Berruguete; en ellos encontraba todo tipo de lenguajes y soluciones compositivas, como muy bien ilustra el imponente Sarcófago de la Orestíada, prestado por el Museo Arqueológico Nacional.

La habilidad de Berruguete en el ejercicio del modelado, tanto en madera como en mármol, en cera preparatoria para el bronce o en alabastro, se pone de manifiesto en otra exquisita obra de esta exposición, Llanto sobre Cristo muerto, perteneciente a la Colección Gregorio Marañón (Fig. 6).

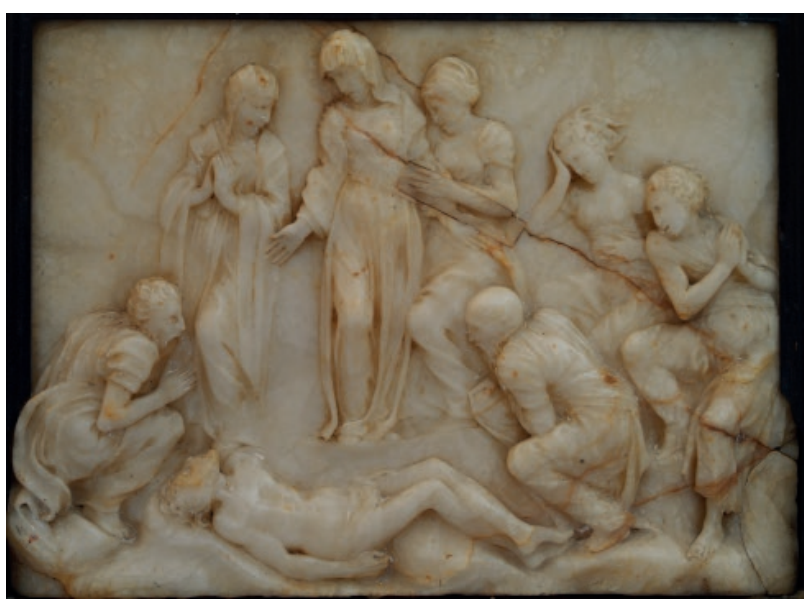

Fig. 6: Alonso Berruguete Llanto sobre Cristo muerto

Colección Gregorio Marañón

E1 Museo Nacional de Escultura ha aprovechado esta oportunidad para sacar a la luz algunas obras que habitualmente permanecen guardadas en su almacén y llevar a cabo una laboriosa intervención de restauración para su puesta en valor en una muestra. Es el caso de la gran Venera del Retablo de San Benito el Real, que se expone por primera vez.

A pesar de su arriesgada propuesta artística, Berruguete gozó ya en vida de especial fortuna crítica. Como si la diosa Fortuna hubiese infundido su halo protector sobre él, permitiéndole estar en Roma en el momento adecuado y a su vuelta a España gozar de la protección real. Arias Martínez manifiesta que "Berruguete se convirtió en el escultor por excelencia del siglo XVI, en la mejor expresión del genio nacional, en el renovador de las formas [...] en el introductor del nuevo lenguaje renacentista [...]" (2017: 83).

Curiosamente, desde la perspectiva de la pintura, sus cuadros resultan algo extraños a la vista. Podríamos incluso decir que parece detectarse cierta torpeza en su ejecución, son pinturas en ocasiones muy planas e inacabadas. Sorprende que Berruguete sea capaz de dominar la técnica escultórica en diversos materiales y sin embargo no sea capaz de trasladar ese carácter escultórico a sus pinturas; esto podría deberse a la 
intervención de otros pupilos de su taller, costumbre habitual en la época; o a que su preocupación primordial era la búsqueda de la expresividad. En este sentido, no nos extrañaría que Berruguete hubiese dado supremacía a la escultura sobre la pintura. No haría sino seguir la teoría Plotiniana -apoyada por Miguel Ángel-, según la cual el arte está en el bloque, sobre el que el artista ejerce un trabajo de extracción. Berruguete además de extraer la forma artística, aporta la cualidad de la expresividad, que es una cualidad subjetiva. El Laocoonte es expresión por antonomasia y Berruguete es hijo del Laocoonte y, por ende, pura expresividad.

\section{"Otros" Laocoontes}

Nos parece oportuno plantear, como posible línea de investigación, un "nuevo puente" entre Berruguete, el subjetivismo romántico y el expresionismo. Un puente como el que creó el grupo expresionista Die Brücke reivindicando su filiación directa respecto a los antiguos maestros, pero en este caso tomando como hilo conductor el valor expresivo del arte, sea cual sea su lenguaje formal.

Ya hemos visto que el descubrimiento del Laocoonte fue trascendental para todo el mundo occidental desde el punto de vista histórico-artístico. El hallazgo del Laocoonte generó también uno de los debates estéticos más interesantes: el provocado por Gotthold Ephraim Lessing (1729-1781), uno de los críticos más grandes de todas las épocas. Lessing, que con su Laocoonte o los límites de la pintura y de la poesía (1766) ejerció gran influencia sobre la crítica de arte en la cultura occidental, expone un parangone entre los límites de las artes plásticas y la poesía, considerando a esta capaz de expresar ilimitadamente todos los sentimientos y pasiones ${ }^{5}$.

Tanto Berruguete como Lessing toman el conjunto escultórico del Laocoonte como punto de partida de sus creaciones e investigaciones. También hoy el Laocoonte está en la génesis de esta exposición.

Una boca demasiado abierta, en pintura, se refleja a través de una mancha, y en escultura, a través de un hoyo; son recursos formales que producen un efecto de desagrado. Pero aunque, entre los antiguos, la belleza era la primera ley de las artes plásticas, el conjunto del Laocoonte nos sorprende mostrándonos el sufrimiento del sacerdote troyano reflejado en su rostro y en toda su anatomía. Lessing dice que "su dolor nos llega al alma"6 y se nos presenta aún hoy con una visión muy moderna y atemporal:

Pero, como ya lo hemos observado, el arte, en los tiempos modernos, ha extendido sus límites incomparablemente mucho más lejos. Su imitación, se dice, abarca toda la naturaleza visible, cuya belleza no es más que una pequeña parte; la verdad y la expresión constituyen su primera ley, y como la misma naturaleza sacrifica a cada instante la belleza a puntos de vista más elevados, así también el artista debe de subordinarla a su plan general sin rebuscarla más de lo que permitan la verdad y la expresión. Basta con que, por la verdad y la expresión, lo feo de la naturaleza se transforme en lo bello del arte (Lessing, 2012, capítulo III).

5 Sin embargo Lessing no había podido contemplar con sus propios ojos los monumentos originales de la Antigüedad. Aquellas hermosas obras de "noble sencillez y serena grandeza" que mencionaba Johann Winckelmann (1717-1768) en sus Reflexiones sobre la imitación de la pintura y la escultura (1765) o en la Historia del Arte Antiguo (1764).

6 Lessing, Gotthold Ephraim, ed. 2012. Laocoonte o sobre los límites de la pintura y de la poesía. Madrid. Ediciones Ibéricas - Colección La Crítica Literaria, www.LaCriticaLiteraria.com. Capítulo I. 
Al igual que el grito del Laocoonte es el paradigma de la expresión del dolor en la Antigüedad, un cuadro como El grito de Edvard Munch (1863-1944) podría ser la expresión moderna de un grito de silenciosa desesperación. Nos encontramos ante la delgada línea que divide lo bello y lo feo, el goce y el dolor en el arte, lo apolíneo y lo dionisíaco. El Laocoonte puede ser bello y feo al mismo tiempo, puede causar goce o dolor.

Vasily Kandinsky (1866-1944) decía que existe una belleza exterior, a la que están habituadas la mayoría de las personas, y una belleza interior, "que es la que renuncia a la belleza exterior habitual y que normalmente parece fea al que no está acostumbrado a ella, pues el ser humano en general tiende a lo externo"7.

El arte expresa un instante único y se dejan a la imaginación todos los sentimientos e ideas que rodean ese instante. Nos abandonamos, pues, a la proyección sentimental (Einfühlung) $^{8}$.

La teoría de la proyección sentimental, que más tarde desarrolló Wilhelm Worringer (1881-1965) ${ }^{9}$, dio un paso decisivo desde el objetivismo al subjetivismo estéticos; es decir, es el sujeto que contempla la obra de arte quien proyecta o no un valor sentimental en la obra ${ }^{10}$. Worringer decía que la teoría de la proyección sentimental es proyectarse a sí mismo en una obra de arte y penetrar en la obra con el sentimiento. Theodor Lipps (1851-1914) va más allá y opina que "el goce estético es autogoce objetivado", esto es, gozarme en otro objeto de manera que me proyecte en él y penetre en él con mi sentimiento; lo que proyecto en ese objeto es vida, y la vida es vigor, es actividad y por lo tanto es esfuerzo, es un esfuerzo volitivo.

Dice Worringer que el ser humano tiene una necesidad de autoactividad, que es una necesidad fundamental de nuestro ser. Si mi autoactividad coincide con la exigencia que requiere una obra de arte por comprenderla, entonces se produce un sentimiento de libertad, que es un sentimiento de goce. Lipps lo llama "Einfühlung positiva".

La voluntad de "Einfühlung positiva" produce goce estético; en otras palabras, lo que nos produce goce estético es proyectarnos a nosotros mismos en la obra de arte, conocerla, sentirla, gozarla.

Se nos habla del valor de la vida que contiene una forma, pero lo que realmente le da belleza a esa forma es el sentimiento vital que voluntariamente introducimos en ella.

Alois Riegl (1858-1905) comenzó la ruptura contra el materialismo artístico y acomodado, abriendo el camino a una nueva concepción, e introdujo en el método de análisis histórico-artístico el concepto de "voluntad de arte" y "voluntad artística absoluta". Se entiende por "voluntad artística absoluta" una latente exigencia interior, que es el "momento" primario de toda creación artística. Toda obra de arte no es sino una objetivación de esta voluntad artística absoluta. Es decir, el artista convierte su

7 Kandinsky, Vasily: De lo espiritual en el arte, Barral editores, Barcelona, 1973. Edición original Über das Geistige in der Kunst. Piper \& Co., Múnich, 1911.

8 Corriente iniciada por Friedrich Theodor Vischer y Robert Vischer, padre e hijo (1807-1887; 1847-1933), proseguida por Theodor Lipps (1851-1914) y más tarde por Wilhelm Worringer (1881-1965).

9 Worringer, Wilhelm, Ed. 1953. Abstracción y Naturaleza. México. Fondo de Cultura Económica. Edición original, 1908. Abstraktion und Einfühlung. Múnich. Piper \& Co.

10 El problema de la proyección sentimental en el arte se remonta al Romanticismo, cuya intuición artística anticipó la concepción básica de la estética vigente a principios del siglo XX. Theodor Lipps, en su Estética había desarrollado el principio general de la empatía o proyección sentimental (Einfühlung) en la estética de su tiempo. 
voluntad artística en obra de arte.

Sólo a través de un impulso interior, de una voluntad artística absoluta y de una Einfühlung positiva el artista puede llegar a la catarsis; es la catarsis del Laocoonte o la de Berruguete, la de los románticos o de los expresionistas. No en vano, en nuestra opinión, Berruguete es hijo del Laocoonte, pero también podría perfectamente ser padre de los románticos y abuelo de los expresionistas. 